\title{
RHADINOPYGA N. GEN. FROM THE "VOGELKOP" OF NEW GUINEA AND ADJACENT ISLANDS, A NEW GENUS OF THE SUBTRIBE COSMOPSALTRIARIA (HOMOPTERA, CICADOIDEA: CICADIDAE)
}

\author{
by \\ J. P. DUFFELS \\ Institute of Taxonomic Zoology, University of Amsterdam, \\ P.O. Box 20125, 1000 HC Amsterdam, The Netherlands
}

\begin{abstract}
Rhadinopyga $\mathrm{n}$. gen. is erected for Diceropyga recedens (Walker) from Salawati, $D$. impar (Walker) and $D$. acuminata Duffels, both from Waigeo, and Rhadinopyga epiplatys n. sp. from the "Vogelkop" area (=Tjendrawasih) of New Guinea and the islands of Misoöl and Batjan. Phylogenetic analysis suggests a sister-group relationship of Rhadinopyga n. gen. and Diceropyga Stål. The endemism of Rhadinopyga in the "Vogelkop" area is discussed in connection with the geological history of the area and the historical biogeography of the subtribe Cosmopsaltriaria.
\end{abstract}

\section{RÉSUMÉ}

Rhadinopyga n. gen. est érigé pour les espèces Diceropyga recedens (Walker) de Salawati, $D$. impar (Walker) et $D$. acuminata Duffels, les deux de Waigeo, et Rhadinopyga epiplatys n. sp. du "Vogelkop" ( = Tjendrawasih) de Nouvelle Guinée et des îles Misoöl et Batjan. L'analyse phylogénétique suggère que Rhadinopyga n. gen. et Diceropyga Stål sont des taxa-sceurs. Le caractère endémique de Rhadinopyga dans la zone du "Vogelkop" est discuté en relation avec l'histoire géologique de la zone et avec la biogéographie historique de la sous-tribu Cosmopsaltriaria.

\section{INTRODUCTION}

In my revision of the genus Diceropyga Stål (Duffels, 1977) I introduced the Diceropyga recedens group for three species: $D$. recedens (Walker, 1868) from Salawati, D. impar (Walker, 1868) from Waigeo, and $D$. acuminata Duffels, 1977 from Waigeo. The group was recognized on account of external and genitalia characters (Duffels, 1977: 104). However, no synapomorphies for the group as a whole were discovered (Duffels, 1977: 212, fig. 264).

A recent study of the cicadas of the Museum Zoologicum Bogoriense, Bogor (MZB) revealed a series of a new species of the recedens group, which is described here from Sorong in the "Vogelkop" ( = Tjendrawasih) of New Guinea and from the islands of Misoöl and Batjan. An additional specimen of this species from Misoöl was found by Mr. M. R. de Jong (Institute of Taxonomic Zoology, Amsterdam) in the collection of the Naturhistoriska Riksmuseet, Stockholm (NRS). Moreover, singletons of other undescribed species from several localities in the "Vogelkop" of New Guinea, in the collections of the Bogor Museum and the Institut Royal des Sciences Naturelles, Brussels, demonstrate that at least five more species belonging to the recedens group await description. The new material provides the opportunity to re-study the recedens group on the basis of more species and more specimens. Phylogenetic analysis of the characters of the taxa of the subtribe Cosmopsaltriaria leads now to the erection of the new genus Rhadinopyga for the three species of the recedens group and the new species, Rhadinopyga epiplatys.

\section{TAXONOMY}

Rhadinopyga $n$. gen.

Type-species. - Dundubia recedens Walker, 1868.

Diagnosis. - Postclypeus weakly produced; each of transverse furrows on underside of postclypeus ending laterally in a short file of 3-7 short ridges. Head including eyes slightly broader than pronotum. Lateral margin of pronotum ampliate with weak tooth. Mesonotum 
much narrower than head. Tegmina and wings hyaline; tegmina with infuscations at bases of 2nd and 3rd apical areas. Abdomen 1.1-1.2 times as long as head and thorax together and marked with transverse fasciae. Male pygofer basally broad; cup of pygofer broad and shallow. Lateral process of pygofer in lateral view strongly narrowed to a recurved, slender apex, which reaches just beyond or somewhat farther beyond the anal valves. Claspers well developed. Lateral and median uncus lobes wanting. Appendages of aedeagus variable.

\section{Rhadinopyga epiplatys $n$. sp.}

(Figs. 1-10)

Material. - Holotype: "N.W. New Guinea, Sorong, 28.VIII-6.IX.1948, M. A. Lieftinck", o' (MZB).

Paratypes: "Misool Id. (W.), 0-75 m, 8.IX-20.X.1948, M. A. Lieftinck", 15 ○ $\sigma^{\circ} 1$ Q (MZB): "Mvsol. Stevens". “"286/84”. " aff obtecta F. quoad formam capitis et thoracis", 1 O" (NRS); "Batjan, Wajana, 14.VII.1953', 1 ơ (MZB).

Description. - Ground colour of head, thorax and abdomen brownish; pronotum, timbal coverings and opercula sometimes with greenish tinge.

Head. Vertex with trilobate black mark around ocelli; black colour around median ocellus extending forward to frontoclypeal suture. A pair of small black spots, situated laterally of paired ocelli, often narrowly connected with black rings around paired ocelli. The narrowly black inner margin of the eye halfway up provided with a black tongueshaped mark. Vertex lobe with a transverse brownish spot, which is not connected with a similar transverse spot on supra-antennal plate. Postclypeus anteriorly with 4-5 transverse brownish lines, which are joined in a median arcuate line; lower part of postclypeus with a median line of very variable width and length, sometimes reaching clypeal suture. Underside of postclypeus with six to seven ridges. The furrows between these ridges end laterally in short files of 3-7 short, brownish ridges (fig. 3). Medial corner of mandibular plate black. Black apex of rostrum reaching just beyond hind coxae.
Thorax. Central fasciae on pronotum narrow, ending in a pair of triangular black spots at anterior margin of pronotum and in a pair of halfmoon-shaped black spots in front of pronotum collar. Anterior oblique fissure ending anteriorly in a small, dark, triangular spot; a pair of narrow dark brown lines is situated above these fissures and may be connected with the central fasciae. Posterior oblique fissures ending posteriorly in a dark spot, which continues in the dark coloured lateral part of ambient fissure. A dark spot is situated between anterior and posterior oblique fissures. Mesonotum with black median fascia reaching from anterior margin of mesonotum to cruciform elevation; anterior third of median fascia three to four times as broad as narrow part at midlength; posterior part about six times as wide as the narrowest part. Paramedian fasciae slightly converging to about halfway across mesonotum disk and widening toward distal end, which is a black dot at the medial side of the fascia. A pair of black dots is situated in front of the anterior angles of the cruciform elevation. Lateral fasciae conspicuous and often somewhat irregularly shaped, sometimes running along whole length of mesonotum, but often subdivided in a black fascia on posterior half of mesonotum, a much smaller spot at about one third of mesonotum length, and a small spot at anterior margin of mesonotum. A small black triangle is situated at the anterior margin of the mesonotum between the paramedian and lateral fasciae.

Legs. Ochraceous to light brownish. Fore femur with two brown spines along brown coloured underridge; inner side with brown line along whole length of femur. Middle and hind femora with faint brownish streaks on both sides. Fore and middle tibiae often darkened to their distal ends. Fore and middle tarsi only apically dark coloured.

Tegmina and wings. Hyaline. Basal venation light brownish, turning brownish apically. Basal veins of 2 nd and 3rd apical areas of tegmen infuscated.

Male. - Operculum. Light brownish, often with greenish tinge; basal one third of lateral 

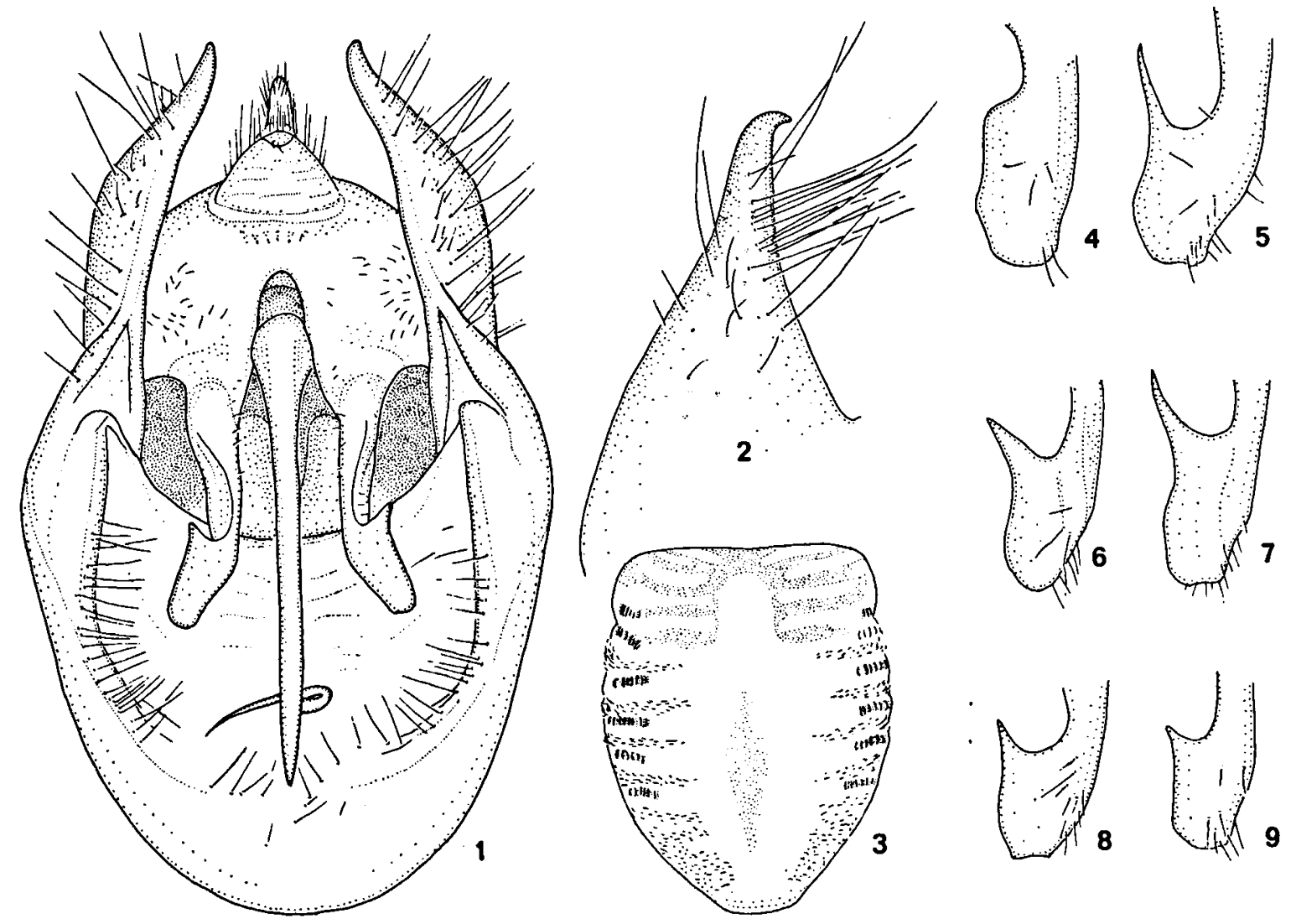

Figs. 1-9. Rhadinopyga epiplatys n. sp.: 1, pygofer in ventral view, holotype; 2, lateral process of pygofer in lateral view, holotype; 3, postclypeus in ventral view, holotype; 4-9, apex of clasper: 4, 5, 7, 8, 9, paratypes from Misoöl, 6, paratype from Batjan.

margin with very narrow black line; some specimens have a narrow black line along the medial margin. Operculum reaching posterior margin of 5th to 6 th abdominal segment. Lateral margin fairly strongly incurved at one fourth of length, apical part convex; medial margin evenly convex up to narrowly rounded apex, which is distinctly outcurved.

Abdomen. Dorsally dark to light brown. Segment 2 with a dark brown basal mark reaching from anterior margin of segment to two thirds of the segment's length medially and to half its length laterally. Segments 3-7 dorsally brown to dark brown with posterior one fifth to one fourth lighter coloured. Most conspicuous are the snow-white lateral marks of wax on segment 3 , which are 1.5-2 times as broad as long and reach from anterior margin of segment to halfway along the segment; medial part of segment 3 between these marks as dark as mark on segment 2. Anterior one third to half of segment 8 brownish, posterior part lighter. Underside light brown, with exception of anterior two thirds or nearly whole sternite 7 and pleurites of segments 6 and 7 being dark brown.

Genitalia. Lateral process of pygofer reaching just beyond anal valves (fig. 1), in lateral view suddenly narrowing to the slender recurved apex (fig. 2). The long and straight flattened claspers bear an apical, flat hook, which is variable in shape (figs. 4-9), but always 1.5-2 times as long as broad. Median bend of segment 10 between claspers a little above the level of distal corners of basal pygofer lobes. 
Aedeagus with strongly chitinized, acute apex with a very slender, curved subapical rod and a pair of short thorns placed more proximally at underside of aedeagus.

Female. - Operculum. Light brown, reaching to one third of length of segment 2 . Laterobasal corner black. Lateral margin straight with a narrow dark line. Posterior margin fairly strongly undulate, laterodistal corner rounded.

Abdomen. Dorsal side with triangular dark brown spot at anterior margin of segment 2 and round lateral spots on segments 3-7. Posterior dorsal halves or one thirds of segments 4-8 somewhat lighter than anterior parts. Sternite 7 dark brown. Segment 9 dorsally with a pair of paramedian, triangular, black marks reaching from anterior margin to three fourths of segment, laterally black coloured along anterior margin and ventrally with a pair of brownish spots and brownish bordered undermargins.

Measurements. - Body length: $\sigma^{\prime \prime}, 24-28$ $\mathrm{mm}$; \&, $21 \mathrm{~mm}$. Tegmen length: $\sigma^{*}, 35.5-37.5$ $\mathrm{mm}$; , $35.5 \mathrm{~mm}$. Head width: $\sigma^{\circ}, 8.7-9.5$ $\mathrm{mm}$; $\$$, $8.9 \mathrm{~mm}$. Pronotum width: $\sigma^{\circ}, 8.5-9.4$ $\mathrm{mm}$; \&, $9.3 \mathrm{~mm}$. Mesonotum width: $\sigma^{\circ}$, 7.5-8.1 mm; $९, 8.0 \mathrm{~mm}$.

Remark. $-R$. epiplatys is most closely related to recedens but can be distinguished from this species by the conspicuous lateral marks of white wax on abdominal segment 3 , the long and broad apical lobes of the claspers and the more proximal medial bend of segment 10 between the claspers.

Et ymology. - The generic name Rhadinopyga is derived from the Greek pootvós meaning slender, plus the frequently used suffix "pyga", from the Greek $\pi u \gamma^{\prime}$, which refers to the terminal abdominal segments. The specific name is derived from the Greek $\varepsilon \pi \iota \pi \lambda \alpha \tau$ v broad-lobed.

\section{PHYLOGENY}

The monophyly of the four described and five undescribed species of Rhadinopyga is presumed on account of the following synapomorphies: the peculiar shape of the lateral process of the pygofer, which is fairly long and strongly narrowed to a slender, recurved apex in lateral view (fig. 2) and the broad basal part of the male pygofer enclosing a broad and shallow cup (fig. 1). Rhadinopyga is the sister-group of Diceropyga. Both genera share a very interesting synapomorphy, which has been discovered recently viz., the presence of files of short ridges at the lateral ends of the transverse furrows on the postclypeus (fig. 3). This feature is neither found in the other genera of the Cosmopsaltriaria nor in any other cicada.

\section{BIOGEOGRAPHY}

The nine species of Rhadinopyga recognized are restricted to the "Vogelkop" area of New Guinea and the adjacent islands (cf. fig. 10). The sister-genus Diceropyga is distributed in Maluku, the north-coast mountains of New

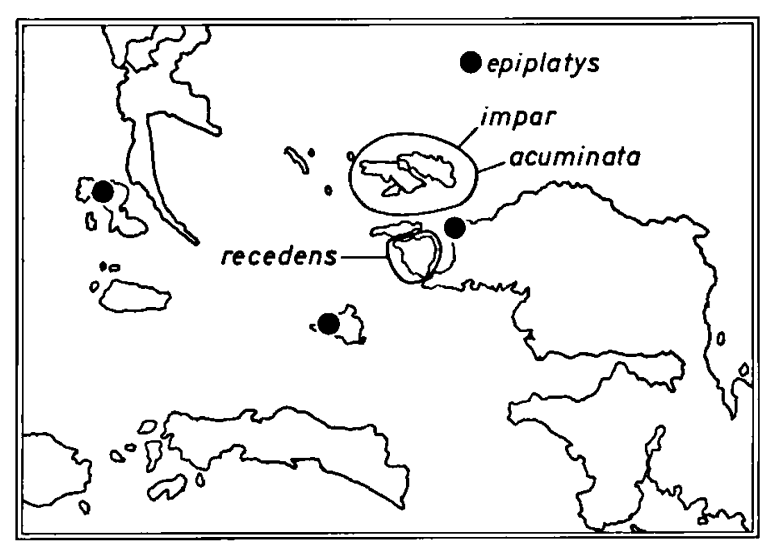

Fig. 10. Distribution of the described species of Rhadinopyga in the "Vogelkop" of New Guinea and adjacent islands.

Guinea, the Papuan Peninsula, Bismarck Archipelago and Solomon Islands. The distribution of Diceropyga has been recognized as a Maluku and western Outer Melanesian Arc distribution (Duffels, 1983a, b). The Outer Melanesian Arc is formed by the north-coast mountains of New Guinea, the Bismarck Ar- 
chipelago, Solomon Islands, Vanuatu ( $=$ New Hebrides) and Fiji Islands (for reviews of the geology of the Southwest Pacific see: Crook, 1981, and Holloway, 1984). This Outer Melanesian Arc is a Tertiary island arc of oceanic derivation, that collided with the continental, Australian part of New Guinea in the Late Miocene or Pliocene.

The continental part of New Guinea is a fragment of the Inner Melanesian Arc. The geological history of this fragment reveals extension of land area since the middle of the Tertiary, major uplift in the Pliocene and orogeny in the Pliocene and Pleistocene leading to the formation of the central mountain ranges of New Guinea. The oceanic northern (Outer Arc) part and the continental central (Inner Arc) part of New Guinea were separated by a water gap until the Pliocene. In biogeographic respect it is most interesting that no representatives of Diceropyga are found in the "Vogelkop" and adjacent islands, whereas Rhadinopyga is restricted to this area. The only overlap of the two genera is found in Batjan.

The "Vogelkop" and its continental shelf has been torn away from a position adjacent to what is now the shelf edge of northwestern Australia, probably in the Neogene (Hamilton, 1979). The northern part of the "Vogelkop" and the adjacent islands are considered a part of the Outer Melanesian Arc, whereas the southern part is supposed to be a continuation of the Inner Melanesian Arc (Holloway, 1984: fig. 1). However, the absence of Diceropyga in the "Vogelkop" and the restriction of its sistergenus Rhadinopyga to this area suggests an isolated position of the "Vogelkop" and adjacent islands among the western fragments of the Outer Melanesian Arc.

\section{ACKNOWLEDGEMENTS}

Mr. M. R. de Jong (Institute of Taxonomic Zoology, Amsterdam) contributed to this paper by stimulating discussions. My sincere thanks are due to my colleague Dr. W. N. Ellis (Institute of Taxonomic Zoology, Amsterdam) for critical reading this paper. I am very much indebted to Dr. S. Adisoemarto (Museum Zoologicum Bogoriense, Bogor), Dr. P. Lindskog (Naturhistoriska Riksmuseet, Stockholm) and to Mr. R. Détry (Institut Royal des Sciences Naturelles de Belgique, Brussels) for the loan of material. A grant from the Netherlands Foundation for the Advancement of Tropical Research (WOTRO, no. WR85-197) enabled me to study the collection of the Museum Zoologicum Bogoriense.

\section{REFERENCES}

Crook, K. A. W., 1981. The break-up of the AustralianAntarctica segment of Gondwanaland. In: A. KeAsT ed., Ecological biogeography of Australia. Monographiae biol., 41: 3-14 (Junk, The Hague).

Duffels, J. P., 1977. A revision of the genus Diceropyga Stål, 1870 (Homoptera, Cicadidae). Monografieën Ned. ent. Vereen., 8: 1-227.

- - 1983a. Taxonomy, phylogeny and biogeography of the genus Cosmopsaltria, with remarks on the historic biogeography of the subtribe Cosmopsaltriaria (Homoptera: Cicadidae). Pacific Insects Monogr., 39: 1-127.

-, 1983 b. Distribution patterns of Oriental Cicadoidea (Homoptera) East of Wallace's Line and plate tectonics. In: I. W. B. Thornton ed., Symposium on distribution and evolution of Pacific insects. Geojournal, 7 (6): 479-564.

Hamilton, W., 1979. Tectonics of the Indonesian region. Geol. Surv. prof. Pap., 1078: i-ix, 1-345 (U.S. Government Printing Office, Washington).

Holloway, J. D., 1984. Lepidoptera and the Melanesian Arcs. In: F. J. Radovsky, P. H. Raven \& S. H. SoHmer eds., Biogeography of the tropical Pacific: 129-169 (Association of Systematics Collections, Lawrence, U.S.A.). 